\title{
Sternal closure methods in high-risk patients: Should they be specific to the patient?
}

\author{
Metin Onur Beyaz ${ }^{\mathrm{a},}$, Ibrahim Demir $^{\mathrm{b}}$, Atalay Karakaya $^{\mathrm{a}}$, Mustafa Ozer Ulukan $^{\mathrm{a}}$, Korhan Erkanll $^{\mathrm{a}}$
}

${ }^{a}$ Department of Cardiovascular Surgery, Faculty of Medicine, Istanbul Medipol University, Istanbul, Turkey.

${ }^{b}$ Department of Cardiovascular Surgery, Faculty of Medicine, Istanbul University, Istanbul, Turkey.

\begin{abstract}
Background: To analyze and investigate the most effective sternum closure method in high-risk patients undergoing median sternotomy, we compared a steel wire-titanium hooks combination with a steel wiretitanium plates and screws combination.

Patients and Methods: We examined 67 patients who underwent median sternotomy between October 2018 and January 2020. Patients who needed postoperative chemotherapy or radiotherapy due to malignancy were excluded from the study. The patients were randomly divided into two groups with similar risk factors. In the first group, a steel wire-titanium hooks combination was used to close the sternum. A steel wire-titanium plates and screws combination was used in the second group of patients.

Results: No dehiscence or mediastinitis were observed in either patient group. Superficial wound infection was seen in four patients from each group and was successfully treated with antibiotic therapy. There was no significant difference between the two groups regarding the intensive care stay, the duration of hospitalization, the amount of bleeding or the need for re-exploration ( $p>0.05)$.

Conclusion: The choice between sternal closure techniques in high-risk patients should be mainly based on the characteristics of the patient. Beyond this, the most cost-effective method in which the surgeon is most experienced should be preferred.
\end{abstract}

Keywords: Titanium hooks; titanium plates and screws; tersonalized sternal closure methods

\section{INTRODUCTION}

Cardiovascular surgeons have not abandoned costeffective steel wire choices for sternum closure ${ }^{[1]}$. Sternal dehiscence is the riskiest complication that can occur after a median sternotomy ${ }^{[2]}$. Elderly age, osteoporosis, diabetes mellitus, obesity (BMI> 30), and female gender are risk factors for dehiscence ${ }^{[3]}$. Techniques such as the Robicsek procedure are available

\footnotetext{
* Corresponding author: Metin Onur Beyaz

Mailing address: Department of Cardiovascular Surgery, Faculty of Medicine, Istanbul Medipol Mega University Hospita, TEM Avrupa Otoyolu Goztepe Cikisi, No:1, 34214 Bagcilar, Istanbul, Turkey.

E-mail: metinonurbeyaz@gmail.com

Received: 19 July 2020 / Accepted: 10 September 2020
}

for patients at risk. However, the application of any method involving the use of steel wire is still controversial in high-risk patients ${ }^{[4,5]}$. With advances in technology, classical sternal closure methods have been replaced by new techniques using titanium plates, titanium hooks [Talon], thermoreactive nitinol clips, flat wire sternal closure systems, plastic materials and titanium cables ${ }^{[6,7]}$. These new sternal closure methods have high costs compared to steel wire. They also extend the operation time and are difficult to implement. Nevertheless, many surgeons prefer new methods over the use of steel wire in patients at risk of dehiscence ${ }^{[8,9]}$. We compared a steel wire-titanium hooks combination with a steel wire-titanium plates and screws combination to investigate the most effective sternum closure method in high-risk patients undergoing median sternotomy. 


\section{PATIENTS AND METHODS}

\section{Materials and methods}

We examined 67 patients due to undergo median sternotomy between October 2018 and January 2020. Patients who needed postoperative chemotherapy or radiotherapy due to malignancy were excluded from the study. The patients were randomly divided into two groups with similar risk factors. In the first group, a steel wire-titanium hooks combination was used to close the sternum. A steel wire-titanium plates and screws combination was used in the second group of patients. Some of the patients included in the study underwent heart valve surgery, while others underwent coronary artery bypass grafting (CABG) surgery. Bilateral internal mammarian artery (IMA) grafting was not used in any of the patients who underwent CABG. We prepared LIMA or RIMA as classic pedicled grafts for patients who required them. The cautery dose did not exceed 20 degrees. We closed the skin with Prolene suture in all patients.

\section{Statistical analysis}

Statistical analysis was performed with the SPSS version 24.0 program (SPSS Inc. Chicago IL, USA). The normal distribution of the variables was examined by histogram graphs and the Kolmogorov-Smirnov test. Mean \pm standard deviation values were used to present the descriptive analyses. The Pearson's chi-square and Fisher's exact tests were compared using $2 \times 2$ tables. Since normally distributed (parametric) variables were evaluated in both groups, a Student's T-test was used. The Mann-Whitney U test was used to evaluate nonparametric variables. Logistic regression tests were performed to obtain the odds ratios. Statistically significant results were determined as P-values below 0.05 .

\section{RESULTS}

The patients were divided into two groups. In the first group, the sternum was closed using a steel wire-titanium hooks combination (Yaylamed Inc). The mean

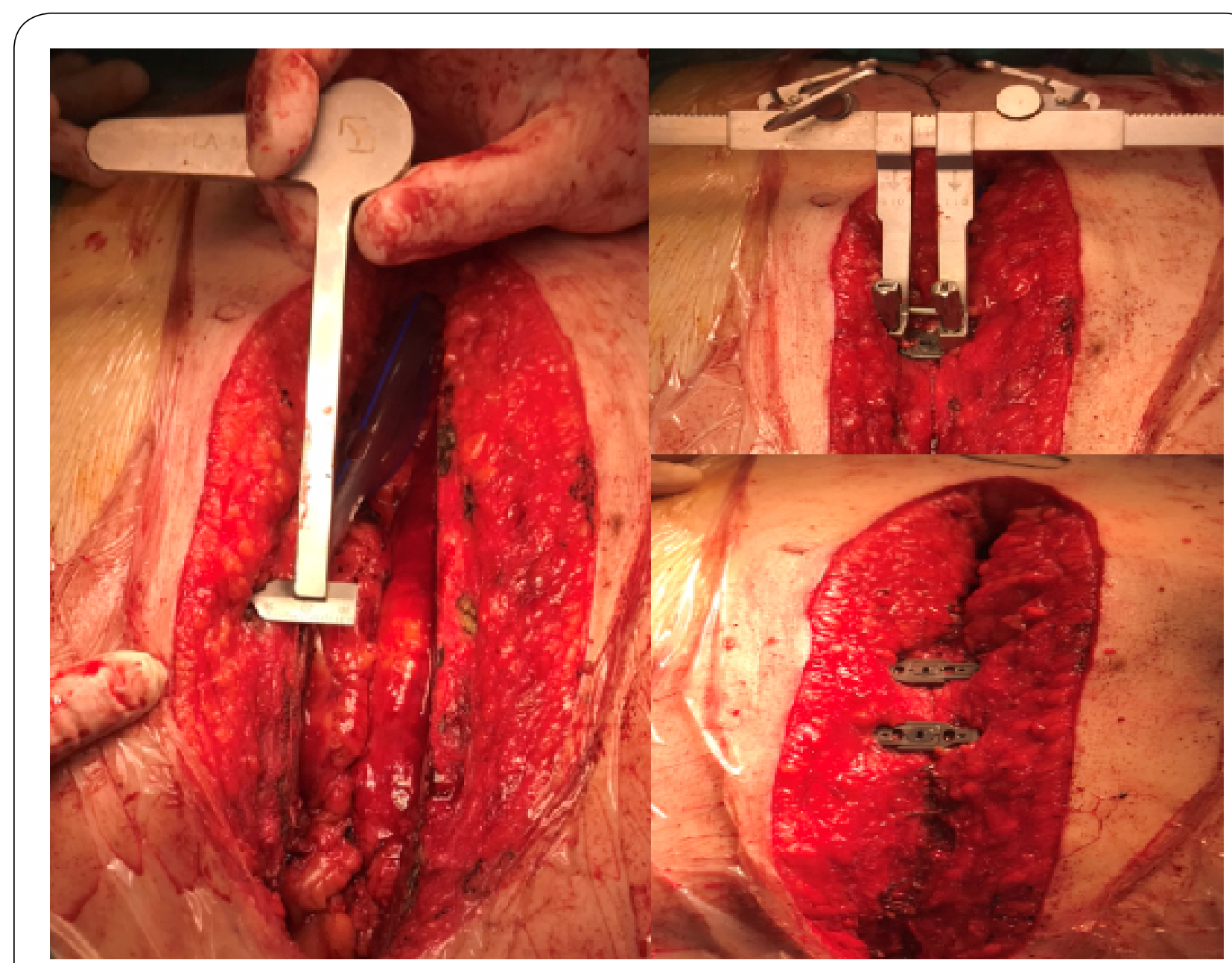

Figure 1. Patient whose sternum was closed using by steel wire and titanium hooks. 


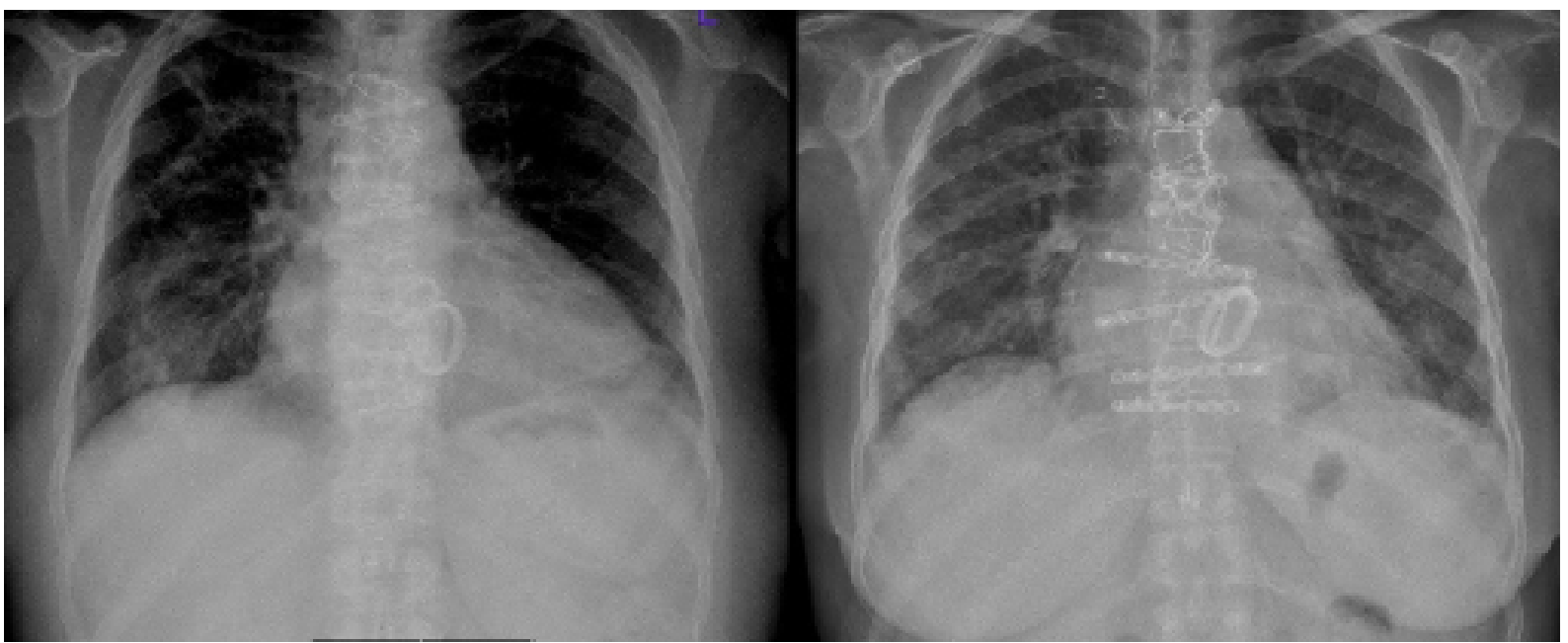

Figure 2. Direct graphy of patient who recieved steel wire-titanium plates and screws.

age of the patients was $65.5 \pm 7.8$ ( $\min 62$-max 73.2), and 18 of the patients $(52.9 \%)$ were women. Diabetes mellitus was present in 14 patients $(41.1 \%)$ (HbA1c: $7.72 \pm 0.9 \%)$, hypertension in $9(26.4 \%)$, and chronic obstructive pulmonary disease (COPD) in 7 (20.58\%) (with $\mathrm{FEV}^{1}<80 \%$ and $\mathrm{FEV}^{1} / \mathrm{FVC}<70 \%$ with spirometry); 19 (55.88\%) patients were smokers (more than 10 pack-years), 8 (23.52\%) were obese (BMI>30 kg/ $\mathrm{m}^{2}$ ), and $26(76.47 \%)$ had multiple comorbidity included osteoporosis.

Table 1. Preoperative patient characteristics.

\begin{tabular}{|c|c|c|c|}
\hline & $\begin{array}{l}\text { Steel wire and } \\
\text { talon } \mathrm{N}=34\end{array}$ & $\begin{array}{l}\text { Steel wire-rigid } \\
\text { plade } N=33\end{array}$ & $\mathbf{P}$ \\
\hline Age & $65.5 \pm 7.8$ & $67.0 \pm 7.1$ & 0.09 \\
\hline Female (\%) & $18(52.9 \%)$ & 17 (51.51\%) & 0.611 \\
\hline DM (\%) & $14(41.1 \%)$ & 7 (21.21\%) & 0.029 \\
\hline HT (\%) & $9(26.4 \%)$ & $6(19.8 \%)$ & 0.07 \\
\hline COPD (\%) & $7(20.58 \%)$ & 7 (21.21\%) & 0.889 \\
\hline Smoker (\%) & $19(55.88 \%)$ & $24(36.3 \%)$ & 0.061 \\
\hline $\begin{array}{l}\text { Obesity } \\
\text { (BMI>30kg/m2) }\end{array}$ & $8(23.52 \%)$ & $5(15.15 \%)$ & 0.113 \\
\hline $\begin{array}{l}\text { Multiple } \\
\text { comorbities (\%) }\end{array}$ & $26(76.47 \%)$ & $24(72.27 \%)$ & 0.892 \\
\hline
\end{tabular}

In the second group, the sternum was closed using steel wires and titanium plates and screws. The average age was recorded as $67 \pm 7.1$ ( $\min 57-\max 74.2$ ), and $17(51.51 \%)$ of the patients were women. Diabetes mellitus was present in 7 patients $(21.21 \%)$ (HbA1c: $7.1 \pm 1.3 \%)$, hypertension in $6(19.8 \%)$, and COPD in 7 (21.21\%) (FEV1 $<80 \%$ and FEV1/FVC $<70 \%$ with spirometry); 24 (36.3\%) patients were smokers (more than 10 pack-years), $5(15.15 \%)$ were obese (BMI>30 $\mathrm{kg} / \mathrm{m} 2)$, and 24 (72.27\%) had multiple comorbidity included osteoporosis.
All patients underwent standard median sternotomy, and operations were performed under cardiopulmonary bypass (CPB) with aortic cross-clamp. Cephalosporin was used in all patients for surgical prophylaxis. The skin, subcutaneous tissue, and sternum were wiped with povidone-iodine in all patients while sternotomies were closed. A steel wire-titanium hooks combination was used in the first group, and a steel wire-sternal plates and screws combination was used in the second group. In the first group, an appropriate size device was selected by measuring the sternum width from the intercostal space. In the second group, the appropriate size device was selected by measuring the depth of the sternum. Six to eight steel wires were applied in both groups. Depending on the sternum structure, two or three titanium hooks were placed in the first group, and three or four titanium plates were placed in the second group. Sternums were stabilized. Subcutaneous tissues were closed individually with $2 / 0$ vicryl, and skin was closed with 2/0 Prolene sutures.

All patients used a sternal corset for 8 weeks postoperatively. None of the patients had dehiscence or needed re-exploration.

Postoperative drainage was $498 \pm 176$ (390-830) cc in the first group and 550 $\pm 182(400-800) \mathrm{cc}$ in the second group. There was no significant difference between the groups in terms of postoperative bleeding amount $(\mathrm{p}>0.05, \mathrm{P}=0.285)$.

The postoperative mechanical ventilation requirement of the patients was $8.2 \pm 2.1(3.9-12.1)$ hours for the first group and 9.1 $\pm 2.3(4.3-11.4)$ hours for the second group. There was no significant difference between the 
two groups $(\mathrm{p}>0.05, \mathrm{P}=0.710)$.

Prolonged inotrope was needed in nine $(26.47 \%)$ patients from the first group and in seven $(21.21 \%)$ patients from the second group. No significant difference was found between the two groups ( $p>0.05, P=$ 0.402).

Table 2. Postoperative follow-up results.

\begin{tabular}{llll}
\hline & $\begin{array}{l}\text { Steel wire and } \\
\text { talon N=34 }\end{array}$ & $\begin{array}{l}\text { Steel wire -rigid } \\
\text { plade N=33 }\end{array}$ & $\mathbf{P}$ \\
\hline $\begin{array}{l}\text { Postoperative } \\
\text { bleeding (ml) }\end{array}$ & $498 \pm 176$ & $550 \pm 182$ & 0.285 \\
Ventilation (hour) & $8.2 \pm 2.1$ & $7.1 \pm 2.3$ & 0.710 \\
Prolonged inotrope & $9(26.47 \%)$ & $7(21.21 \%)$ & 0.402 \\
ICU stay (hour) & $25.7 \pm 11.2$ & $22.9 \pm 9.5$ & 0.128 \\
$\begin{array}{l}\text { Hospital stay (day) } \\
\text { Superficial wound }\end{array}$ & $5.4 \pm 1.8$ & $5.7 \pm 1.7$ & 0.767 \\
infection & $4(11.76 \%)$ & $4(12.12 \%)$ & 0.813 \\
\hline
\end{tabular}

The postoperative intensive care hospitalization time was $25.7 \pm 11.2(22.1-47)$ hours for the first group and $22.9 \pm 9.5(19-48.5)$ hours for the second group. No significant difference was found between the two groups ( $p>0.05, \mathrm{P}=0.128$ ).

The average length of hospital stay was $5.4 \pm 1.8(5-8.8)$ days for the first group and $5.7 \pm 1.7$ (5.1-9) days for the second group. There was no significant difference between the two groups ( $p>0.05, P=0.767$ ).

Superficial tissue infection appeared in four $(11.76 \%)$ patients from the first group and in four (12.12\%) patients from the second group. There was no significant difference between the two groups ( $\mathrm{p}>0.05, \mathrm{P}=$ 0.813 ). Staphylococcus aureus was considered to be the cause of the superficial tissue infections; empirical antibiotic therapy was applied, and wounds were treated. No active microorganisms were found in the control swab cultures. Neither sternal dehiscence nor mediastinitis was observed in either group. Neither aseptic dehiscence nor allergic reaction to the materials used developed in either group.

\section{DISCUSSION}

The risk of dehiscence, which is $2.5 \%$ on average, increases gradually due to increasing age, deterioration in eating habits, obesity, chronic lung diseases and malignancies ${ }^{[3]}$. With technological advances, new materials and techniques for sternal closure have been developed to prevent dehiscence in patients with these increased risks ${ }^{[10]}$. High-cost, difficult-to-apply, but highly durable systems have been developed using materials such as titanium plates, titanium hooks, thermoreactive nitinol clips, flat wire sternal closure systems, kryptonite bone glues, plastics, and titanium cables ${ }^{[11]}$.

Cardiovascular surgeons have to fight for different reasons in almost every patient have risk of dehiscence. Sternal dehiscence may develop due to advanced age, female gender, obesity, or osteoporotic bone structure ${ }^{[12]}$. Sudden cough crises increase intrathoracic pressure in smokers and those with COPD. Increased pressure may lead to the breaking of sternal bone structures and the formation of dehiscence in patients whose sternums are closed with traditional steel methods ${ }^{[13]}$. In our study, female sex was dominant in both groups. In addition to gender, smoking, and diabetes were common risk factors in the first group. In the second group, COPD was found at a rate equal to that of diabetes.

The use of titanium plates is still controversial in the presence of osteoporosis ${ }^{[14]}$. One study reported that titanium hooks can be used, especially in patients at risk of dehiscence. However, the possibility of intercostal arterial injury should be considered ${ }^{[15,16]}$. In our study, no complication due to osteoporosis arose during screwing in the patient group in which steel wire and titanium plates were combined. No dehiscence or need for re-exploration were found in these patients. A similar amount of drainage was required in both groups. There was no need for revision due to bleeding, dehiscence, or mediastinitis in any patient in the group where steel wire and titanium hooks were used. Another cause of sternal dehiscence is metal susceptibility caused by hypersensitivity and allergic reaction without exposure to microbial pathogens. Metal hypersensitivity reactions to nickel have been frequently reported ${ }^{[17]}$. In our study, no material other than titanium and steel were used, and no allergic reaction was observed in either group.

\section{LIMITATION}

Randomized studies in which all risk factors are evaluated are required to determine the best routine surgical technique to avoid sternal dehiscence.

\section{CONCLUSION}

The choice between sternal closure techniques in highrisk patients should be based mainly on the characteristics of the patient. Beyond this, the most cost-effective method in which the surgeon is most experienced should be preferred. 


\section{DECLARATIONS}

\section{Authors' contributions}

Made substantial contributions to conception and design of the study and performed data analysis and interpretation: Beyaz MO, Demir I, Erkanlı K.

Performed data acquisition, as well as provided administrative, technical, and material support: Karakaya A, Ulukan MO.

\section{Availability of data and materials}

All data of the patients are stored at Medipol University where the operations are performed.

\section{Conflict of interest}

The author declares that there is no conflict of interest.

\section{Ethical disclosure}

We studied in accordance with the ethical guidelines set by the Helsinki Declaration and the International Association of Heart and Lung Transplantation (ISHLT). A retrospective study was made by obtaining signed documents and approvals from all patients for procedures, including the approval of the use of patient data in future retrospective studies. 10840098-604.01.01E.19387 numbered, 03/07/2020 dated ethics committee permission from Istanbul Medipol University is available for this study.

\section{REFERENCES}

1. Losanoff, J. E., Jones, J. W., \& Richman, B. W. (2002). Primary closure of median sternotomy: techniques and principles. Cardiovascular Surgery, 10(2), 102-110.

2. Kamiya, H., Al-maisary, S. S., Akhyari, P., Ruhparwar, A., Kallenbach, K., Lichtenberg, A., \& Karck, M. (2012). The number of wires for sternal closure has a significant influence on sternal complications in high-risk patients. Interactive cardiovascular and thoracic surgery, 15(4), 665-670.

3. Molina, J. E., Lew, R. S. L., \& Hyland, K. J. (2004). Postoperative sternal dehiscence in obese patients: incidence and prevention. The Annals of thoracic surgery, 78(3), 912-917.

4. Robicsek, F., Daugherty, H. K., \& Cook, J. W. (1977). The prevention and treatment of sternum separation following open-heart surgery. The Journal of thoracic and cardiovascular surgery, 73(2), 267-268.

5. Takazawa K, Ishikawa N, Miyagawa H, Yamamoto T, \& Hariya. A. (2003). Artif Organları, 6 (1): 71-72.

6. Sharma, R., Puri, D., Panigrahi, B. P., \& Virdi, I. S. (2004). A modified parasternal wire technique for prevention and treatment of sternal dehiscence. The Annals of thoracic surgery, 77(1), 210-213.

7. Cataneo, D. C., Dos Reis, T. A., Felisberto Jr, G., Rodrigues, O. R., \& Cataneo, A. J. (2019). New sternal closure methods versus the standard closure method: systematic review and meta-analysis. Interactive cardiovascular and thoracic surgery, 28(3), 432-440.

8. Pai, S., Gunja, N. J., Dupak, E. L., McMahon, N. L., Coburn, J. C., Lalikos, J. F., ... \& Billiar, K. L. (2007). A mechanical study of rigid plate configurations for sternal fixation. Annals of Biomedical Engineering, 35(5), 808-816.

9. Snyder, C. W., Graham, L. A., Byers, R. E., \& Holman, W. L. (2009). Primary sternal plating to prevent sternal wound complications after cardiac surgery: early experience and patterns of failure. Interactive cardiovascular and thoracic surgery, 9(5), 763-766.

10. Raman, J., Lehmann, S., Zehr, K., De Guzman, B. J., Aklog, L., Garrett, H. E., ... \& Wong, M. S. (2012). Sternal closure with rigid plate fixation versus wire closure: a randomized controlled multicenter trial. The Annals of thoracic surgery, 94(6), 1854-1861.

11. Tewarie, L. S., Menon, A. K., Hatam, N., Amerini, A., Moza, A. K., Autschbach, R., \& Goetzenich, A. (2012). Prevention of sternal dehiscence with the Sternum External Fixation (Stern-E-Fix) corset-a randomized trial in 750 patients. Journal of cardiothoracic surgery, 7(1), 1-8.

12. Schimmer, C., Reents, W., \& Elert, O. (2006). Primary closure of median sternotomy: a survey of all German surgical heart centers and a review of the literature concerning sternal closure technique. The Thoracic and cardiovascular surgeon, 54(06), 408-413.

13. Celik, S., Kirbas, A., Gurer, O., Yildiz, Y., \& Isik, O. (2011). Sternal dehiscence in patients with moderate and severe chronic obstructive pulmonary disease undergoing cardiac surgery: the value of supportive thorax vests. The Journal of Thoracic and Cardiovascular Surgery, 141(6), 1398-1402.

14. Lazar, H. L., Salm, T. V., Engelman, R., Orgill, D., \& Gordon, S. (2016). Prevention and management of sternal wound infections. The Journal of thoracic and cardiovascular surgery, 152(4), 962.

15. Bennett-Guerrero, E., Phillips-Bute, B., Waweru, P. M., Gaca, J. G., Spann, J. C., \& Milano, C. A. (2011). Pilot study of sternal plating for primary closure of the sternum in cardiac surgical patients. Innovations, 6(6), 382-388.

16. Savage, E. B. (2017). Is rigid sternal fixation really better? Was the correct control group used?. The Journal of Thoracic and Cardiovascular Surgery, 154(6), 20032004.

17. ATA, E. C., \& BOYLU, B. B. (2018). Sternal Steel Wire Induced Persistant Intermittan Mediastinal Wound Drainage After CABG. Türkiye Klinikleri Journal of Case Reports, 26(2), 98-101. 